2014:337(1-2):14-17

doi:10.1016/j.jns.2013.11.007

5. Mayer SA, Copeland D, Bernardini GL, et al. Cost and Outcome of Mechanical Ventilation for Life-Threatening Stroke. Stroke.2000;31(10):2346-
2353. doi:10.1161/01.STR.31.10.2346

6. Walcott BP, Miller JC, Kwon C-S, et al. Outcomes in Severe Middle Cerebral Artery Ischemic Stroke. Neurocrit Care. 2014;21(1):2026. doi:10.1007/s12028-013-9838-x

\title{
BộC Lộ DẤU ẤN HÓA MÔ MIỄN DİCH CK20 TRONG UNG THƯ BIỂU MÔ BÀNG QUANG
}

\section{TÓM TẮT}

Mục tiêu: Nhận xét một số đặc điểm của dấu ân miễn dịch CK 20 và mối liên quan với độ mô học, giai đoạn trong khối u bàng quang phâuu thuật tại bệnh viện Việt Đức. Đối tượng và phương pháp nghiên cứu: Hồi cứu 99 trường hợp ung thư biểu mô bàng quang qua các mẫu bệnh phẩm phẫu thuật tại bệnh viên Viêt Đức. Kết quả: Dấu ấn CK 20 âm tính với 32 trường hợp (32,3\%); dương tính ổ ( $<10 \%$ tế bào $\mathrm{u}$ ) có 27 trường hợp (27,3\%), dương tính lan tỏa có 40 trường hợp (40,4\%). Dấu ấn CK 20 có mối liên quan với đố mô hoc với $\mathrm{p}=0,000<0,05$ và có mối liên quan với giai đoạn bệnh với $p=0,01<0,05$. Các mối liên quan có ý nghĩa thống kê.

Từ khóa: Ung thư biểu mô bàng quang, CK20.

\section{SUMMARY}

\section{EXPRESSION OF CYTOKERATIN 20 IN}

\section{UROTHELIAL CARCINOMA OF BLADDER}

Objectives To evaluate some features of CK 20 immunomarker and its relationship with histological grade, stage in surgical bladder tumor at Viet Duc hospital. Subjects and research methods: A retrospective study was perform in 99 cases of bladder carcinoma through surgical samples at Viet Duc hospital. Results: CK 20 marker was negative in 32 cases $(32.3 \%)$, focal positive ( $<10 \%$ tumor cells) had 27 cases $(27.3 \%)$, diffusely positive had 40 cases (40.4\%). CK 20 marker was related to histological grade with $\mathrm{p}=0.000<0.05$ and related to disease stage with $p=0.01<0.05$. The relationships are statistically significant.

Keywords; Urothelial carcinoma of bladder, cytokeratin 20.

\section{I. ĐẶT VẤN ĐỀ}

Ung thư biểu mô của đường niệu là tổn thương phổ biến nhất trong số ung thư của hệ tiết niệu, trong đó tập trung tại bàng quang khoảng 90-95\%. Tác giả Nguyễn Phúc Cương và

\footnotetext{
${ }^{1}$ Bệnh viện hữu nghi Việt Tiệp

2 Trường đại hoc Y Hà Nôi

Chịu trách nhiệm chính: Nguyễn Trường Giang

Email: truonggiang16121977@gmail.com

Ngày nhân bài: 17.5.2021

Ngày phản biên khoa hoc: 2.7.2021

Ngày duyệt bài: 15.7.2021
}

\section{Nguyễn Trường Giang1, Nguyễn Văn Hưng²}

Nguyễn Sỹ Lánh cho rằng ung thư biểu mô bàng quang chiếm $81,2 \%$ khối u của hệ tiết niệu [1]. Tổ chức y tế thế giới năm 2016 cho biết đây là loại ung thư đứng thứ 7 trong các loại ung thư và chiếm $3,2 \%$ tổng số ca ung thư. Ước tính khoảng 70-80\% bệnh nhân mới chẩn đoán ung thư bàng quang hiện tại với giai đoạn không xâm lấn hoặc đầu xâm lấn (giai đoạn Ta, Tis, hoặc T1) [2]. Cùng với việc phát hiện sớm và định típ mô bênh học thì các yếu tố tiên lượng phân tử của khối u cũng có giá trị cho việc đánh giá mức độ tái phát hay tiến triển của bệnh. Dấu ấn CK20 chỉ dương tính ở lớp tế bào bề mặt hoặc một vài tế bào trung gian của lớp biểu mô bình thường. Khi mức độ bộc lộ vượt quá các giới hạn trên thì có thể gợi ý ung thư biểu mô đường niệu tiến triển, vì trong khối u này dấu ấn CK20 dương tính ở toàn bộ biểu mô của khối u. Chúng tôi nghiên cứu để tài này với mục tiêu: Đánh giá tinh trạng bộc lộ dấu ấn miến dịch CK20 và đối chiêu với typ mô học, độ mô học và giai đoạn bệnh trong ung thư biểu mô niệu bàng quang.

\section{II. ĐỐI TƯỢNG VÀ PHƯƠNG PHÁP NGHIÊN CỨU}

2.1. Đối tượng nghiên cứu. Đối tượng là 99 bệnh nhân UTBQ được cắt bỏ toàn bộ bàng quang chứa u và vét hach, có hồ sơ bênh án và các khối nến lưu trữ tai khoa giải phẫu bênh bệnh viện Hữu Nghị Việt Đức từ tháng 1/2018 đến tháng 3/2019.

\subsubsection{Tiêu chuẩn lựa chọn}

- Các trường hợp phẫu thuật cắt bỏ toàn bộ bàng quang và được chẩn đoán mô bệnh học ung thư biểu mô đường niệu.

- Còn tiêu bản thường quy và khối nến, trong đó, khối nến bệnh phẩm được lưu trữ tốt và còn đủ bệnh phẩm để có thể làm bổ sung xét nghiệm hóa mô miễn dịch.

- Các trường hợp nghiên cứu có hồ sơ bệnh án đủ các thông tin hành chính.

2.1.2. Tiêu chuẩn loại trừ

- Ung thư thứ phát xâm lấn vào bàng quang.

- Ung thư biểu mô đường niệu tái phát. 
- Không có đủ tiêu bản, khối nến bệnh phẩm cũng như thông tin hành chính.

\subsubsection{Các biến số nghiên cứu}

- Tuổi, giới

- Týp mô học, độ mô học, giai đoạn của khối u

- Mức độ bộc lộ dấu ấn CK20

\subsubsection{Tiêu chuẩn đánh giá}

- Giới: có hai biến số là nam và nữ

- Tuổi: phân thành 7 nhóm ( $\leq 29 ; 30-39 ; 40-$ 49; 50-59; 60-69; 70-79; $\geq 80$ )

- Đánh giá độ mô học: Căn cứ WHO 2016 [2] các u typ nhú được phân độ mô học cao và độ mô học thấp, các trường hợp u xâm nhập và biến thể của nó được xếp vào nhóm độ mô học cao.

- Đánh giá typ mô học: Căn cứ bảng phân loại mô học của WHO 2016 [2] (trích dẫn khối u ung thư biểu mô đường niệu xâm nhập và không xâm nhập):

Ung thư BMĐN xâm nhập

+ UTBM đường niệu xẩm nhập biệt hóa théo các hướng khác nhau gồm:

- Biệt hóa vảy

- Biệt hóa tuyến

- Biệt hóa nguyên bào nuôi

+ Biến thể ổ, kể cả ổ lớn.

+ Biến thể vi nang

+ Biến thể vi nhú

+ Biến thể giống lympho biểu mô

+ Biến thể dạng tương bào/tế bào nhẫn/lan tỏa

+ Biến thể dạng sarcoma

+ Biến thể tể bào khổng lồ

+ Biến thể kém biệt hóa

+ Biến thể giàu lipid

+ Biến thể tế bào sáng

+ U xuất phát từ túi thừa bàng quang

\section{KẾT QUẢ NGHIÊN CỨU}

\subsection{Phân bố tuổi và giới}

Bảng 1. Phân bố nhóm tuổi theo giới tính

\begin{tabular}{|c|c|c|c|c|c|c|}
\hline & \multicolumn{2}{|c|}{ Nam } & \multicolumn{2}{c|}{ Nũ } & \multicolumn{2}{c|}{ Tống } \\
\hline Nhóm tuối & $\mathbf{n}$ & $\mathbf{\%}$ & $\mathbf{n}$ & $\mathbf{\%}$ & $\mathbf{n}$ & $\mathbf{0}$ \\
\hline$<=29$ & 0 & 0 & 0 & 0 & 0 & 0 \\
\hline $30-39$ & 2 & 2,2 & 1 & 10 & 3 & 3,0 \\
\hline $40-49$ & 5 & 5,6 & 0 & 0 & 5 & 5,1 \\
\hline $50-59$ & 21 & 23,6 & 3 & 30 & 24 & 24,2 \\
\hline $60-69$ & 26 & 29,2 & 2 & 20 & 28 & 28,3 \\
\hline $70-79$ & 26 & 29,2 & 3 & 30 & 29 & 29,3 \\
\hline$\geq 80$ & 9 & 10,1 & 1 & 10 & 10 & 10,1 \\
\hline Tống Số & 89 & 100 & 10 & 100 & 99 & 100 \\
\hline$X \pm$ SD & $65,83 \pm 11,559$ & \multicolumn{2}{c|}{$64,60 \pm 14,308$} & $65,71 \pm 11,787$ \\
\hline
\end{tabular}

Nhân xét: Tỷ lệ nam/ nữ 8,9/1. Những nhóm tuối thường gặp: 50-59 (24 trường hợp), 60-69 (28 trường hợp) và nhóm 70-79 (29 trường hợp).

Độ tuổi trung bình của cả hai giới là $65,71 \pm 11,787$, trong đó ở nam là $65,83 \pm 11,559$ và ở nữ $64,60 \pm 14,308$. Tỷ lệ mắc bệnh ở các nhóm tuổi giữa nam và nữ không có sự khác biệt. $\mathrm{p}=0,736>0,05$.
Ung thư biểu mô đường niệu không xâm nhập +UTBMĐN tại chố

+UTBMĐN nhú không xâm nhập độ thấp

+UTBMĐN nhú không xâm nhập độ cao

-Đánh giá giai đoạn khối u: Theo WHO 2016

\begin{tabular}{|c|c|}
\hline TX & Không đánh giá được u nguyên phát \\
\hline T0 & Không có u nguyên phát \\
\hline Ta & UTBM nhú không xâm nhập \\
\hline Tis & UTBM tại chố: 'U phẳng' \\
\hline T1 & U xâm nhập mồ liên kết dưới biếu mô \\
\hline T2 & U xâm nhập lớp cơ \\
\hline T2a & U xâm nhập lớp cơ phía nông (nửa trong) \\
\hline T2b & U xâm nhập lớp cơ phía sâu (nửa ngoài) \\
\hline T3 & U xâm nhập mô quanh bàng quang: \\
\hline T3a & Vi thể mới phát hiện được \\
\hline T3b & $\begin{array}{c}\text { Đại thể đã phát hiện được (khối u ngoài } \\
\text { bàng quang) }\end{array}$ \\
\hline
\end{tabular}

T4 U xâm nhập bất cứ cơ quan nào: tiên liệt tuyến T4a U xâm nhập tiền liệt tuyến, tứ cung hoặc

T4b U xâm nhập thành chậu hoặc thành bụng Đánh giá dấu ấn hóa mô miễn dịch CK20:

+ Âm tính: CK20 chỉ bộc lộ giới hạn trong lớp tế bào bề mặt hoặc dưới 3 tế bào ở lớp trung gian của biểu mô đường niệu.

+ Dương tính: Chọn ngưỡng cắt 10\% tế bào u để chia làm 2 loại:

- Dương tính ổ: CK20 bộc lộ ở những lớp sâu hơn hoặc thành ổ $>3$ tế bào ở lớp trung gian hoặc lan tỏa trong biểu mô đường niệu và CK20 dương tính $<10 \%$ tế bào $\mathrm{u}$

- Dương tính lan tỏa khi CK20 dương tính $\geq$ $10 \%$ tế bào u bắt màu ở vùng bộc lộ nhiều nhất. 
3.2. Đặc điểm dấu ấn CK20

Bảng 3.2. Tỷ lệ bộc lộ dấu ấn miễn dịch CK20 theo typ mô học

\begin{tabular}{|c|c|c|c|c|c|}
\hline \multirow{2}{*}{\multicolumn{2}{|c|}{ Typ mô học }} & \multirow{3}{*}{$\frac{\text { CK20 (-) }}{31}$} & \multicolumn{2}{|c|}{ CK20 (+) } & \multirow{2}{*}{ Tổng } \\
\hline & & & ố & Lan tỏa & \\
\hline \multirow{2}{*}{$\begin{array}{c}\text { Nhú đơn } \\
\text { thuân }\end{array}$} & $\mathrm{n}$ & & 17 & 33 & 81 \\
\hline & $\%$ & 38,3 & 21 & 40,7 & 100 \\
\hline \multirow{2}{*}{ Khác } & $\mathrm{n}$ & 1 & 10 & 7 & 18 \\
\hline & $\%$ & 5,6 & 55,6 & 38,8 & 100 \\
\hline \multirow[t]{2}{*}{ Tống } & & 32 & 27 & 40 & 99 \\
\hline & & \multicolumn{3}{|c|}{0,003} & \\
\hline
\end{tabular}

Nhận xét: Ớ nhóm nhú đơn thuân, tỷ lệ CK20(+) (61,7\%) cao hơn CK20(-) (38,3\%). Ở nhóm còn lại, tỷ lệ CK20(+) (94,4\%) cũng cao hơn CK20(-) (5,6\%) với p = 0,003.

3.3. Mối liên quan CK 20 với độ mô học

Bảng 3.3. Mối liên quan giữa đấu ấn miễn dịch CK20 với độ mô học

\begin{tabular}{|c|c|c|c|c|c|}
\hline \multirow{2}{*}{\multicolumn{2}{|c|}{ Độ mô học }} & \multirow{2}{*}{ CK20 (-) } & \multicolumn{2}{|c|}{ CK20 (+) } & \multirow{2}{*}{ Tổng } \\
\hline & & & ố & Lan tỏa & \\
\hline \multirow[b]{2}{*}{ Cao } & $\mathrm{n}$ & 17 & 26 & 38 & 81 \\
\hline & $\%$ & 21,0 & 32,1 & 46,9 & 100 \\
\hline \multirow{2}{*}{ Thấp } & $\mathrm{n}$ & 15 & 1 & 2 & 18 \\
\hline & $\%$ & 83,3 & 5,6 & 11,1 & 100 \\
\hline Tống & $\mathrm{n}$ & 32 & 27 & 40 & 99 \\
\hline \multicolumn{2}{|l|}{5} & \multicolumn{3}{|c|}{0,000} & \\
\hline
\end{tabular}

Nhận xét. Nhóm độ mô học cao có tỷ lệ CK20 (+) (79\%) cao hơn so với nhóm độ mô học thấp $(16,7 \%)$. Hầu hết các trường hợp $(83,3 \%)$ ở nhóm độ mô học thấp có CK20 (-) với $p=0,000$.

3.4. Mối liên quan dấu ấn CK20 với giai đọan bệnh

Bảng 3.4. Mối liên quan giứa dấu ấn miê̂n dịch CK20 với giai đoạn bệnh

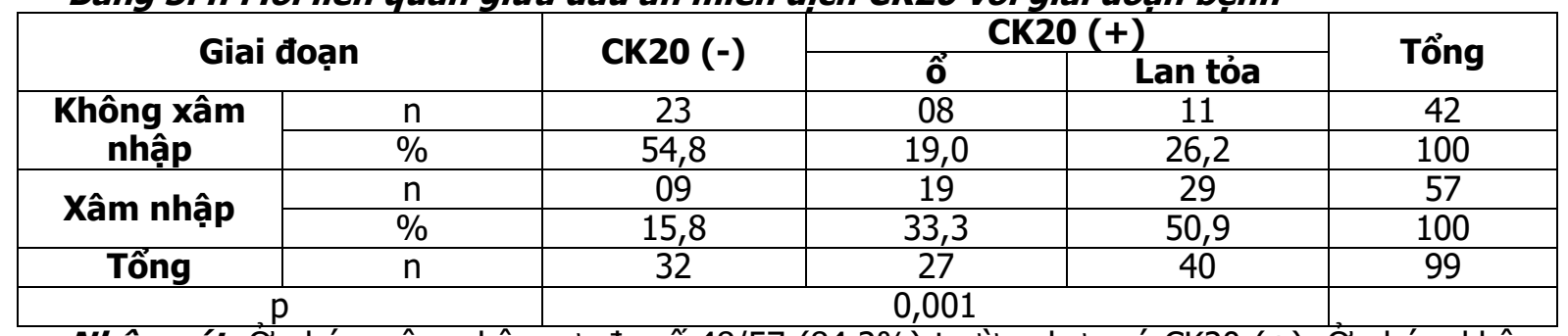

Nhận xét: Ơ̛ nhóm xâm nhập cơ, đa số 48/57 (84,2\%) trường hợp có CK20 (+). Ơ nhóm không xâm nhập, tỷ lệ CK20(+) $(45,2 \%)$ thấp hơn tỷ lệ CK20(-) $(54,8 \%)$ với p $\mathrm{p}=0,001$.

\section{BÀN LUÂN}

4.1. Tuổi và giới. Trong nghiên cứu của chúng tôi với 99 BN có độ tuổi trung bình của nhóm đối tượng nghiên cứu là thay đổi từ 35 đến 85 tuổi. Độ tuổi trung bình chung của cả nam và nữ là $65,71 \pm 11,787$, của nam giới mắc là $65,81 \pm 11,559$, của nữ giới là $64,6 \pm 14,308$. Bệnh nhân trong nhóm từ 50 - 59 tuổi mắc cao nhất có 24 trường hợp chiếm tỷ lệ $24,2 \%$, nhóm từ 60 - 69 tuổi có 28 trường hợp chiếm tỷ lệ 28,3\%, nhóm từ 70-79 tuổi có 29 trường hợp chiếm tỷ lệ 29,3\%. Không có trường hợp nào dưới 30 tuổi. Trong nghiên cứu này tỷ iệ mắc bệnh không thây có sự khác biệt giữa hai giới với $\mathrm{p}=0,736>0,05$. Đánh giá về nhóm tuổi thì phần lớn các tác giả đều có nhận định chung độ tuổi mắc trung bình khoảng trền 60 tuổi, như tác giả Lê Thanh Xuân [3] cho biết độ tuổi trung bình là
$62,73 \pm 11,16$, trong khi đó cho nam giới 60,91 $\pm 9,08$ và của nữ giới là $69,62 \pm 11,18$. Theo tác giả Nguyễn Văn Hưng và Nguyễn Thị Hồng Điệp, độ tuổi trung bình của các đối tượng nghiên cứu là 60,3 ; tuổi thấp nhất là 27 , cao nhất là 84 , nhóm tuổi hay gặp nhất là 50-59 chiếm 31,5\% [4]. Tuy nhiên một số tác giả nước ngoài có thể độ tuổi cao hơn với khoảng 70 tuổi như theo tác giả Bertz và cs[5] cho thấy độ tuổi trung bình cả 2 giới là 71,7 và dao động từ 38-87 tuổi. Nhìn chung các tác giả nước ngoài đều cho thây độ tuổi mắc bệnh cao hơn và thường phát hiện ở giai đoạn sớm hơn chưa xâm nhập cớ. Để lý giải cho điều này cũng phải thấy một điều rất cơ bản là việc đất nước ta còn là đất nước đang phát triển và công nghiệp hóa, hiện đại hóa đất nước nên không tránh khỏi người dân tiếp xúc nhiều với hóa chất cũng cũng như các điều kiện bảo hộ 
lao động còn hạn chế cũng như những thói quen thuốc lá và rượu bia gây ảnh hưởng tới khả năng mắc bênh cao. Bên canh đó viêc khám bênh định kỳ và tầm soát khối u cũng khổng được chúng ta quan tâm nhiều trong khi đó ở các nước phát triển việc khám sức khỏe định kỳ được quan tâm và các thiết bị phương tiện hiện đại. Do vậy cũng là điều dễ hiểu độ tuổi cao hơn và phát hiện giai đoạn sớm hơn so với chúng ta.

4.2. Dấu ấn miễn dịch CK20 và mối liên quan. CK20 chỉ dương tính ở lớp tế bào dù bề mătt hoặc một vài tế bào trung gian của lớp biểu mồ bình thường; tuy nhiên khi mức độ bộc lộ vượt quá các giới hạn trên thì có thể gợi ý ung thư biểu mô đường niệu tiến triển, vì trong khối u này dấu ấn CK20 có thể dương tính ở toàn bộ lớp biểu mô. Một số nghiên cứu cho thây có sự liên quan giữa mức độ bộc lộ CK20 tăng theo độ mô học và giai đoạn [6].

Theo bảng 3.2 đối với bôc lô dẫu ấn CK20 với các khối u bộc lộ âm tính trong nghiên cứu của chúng tôi có 32 ca $(32,3 \%)$ thấp hơn của Lê Thanh Xuân [3] có tới 26/51 ca không bộc lộ CK20 chiếm $51 \%$ hay tác giả Desai và cs nghiên cứu trên 120 ca thây: trong nhóm u giai đoạn ta có $46,6 \%$ bộc lộ bình thường hay âm tính. Ngược lại theo một số tác giả cho kết quả tương tự nghiển cứu của chúng tôi như Harnden và cs nghiên cứu các khối u chưa xâm nhập có kết quả bộc lộ âm tính 39,1\% hoặc như tác giả Burge và cs [7] nghiên cứu 71 BN thây $40 \%$ bộc lộ bình thường. Bên canh đó tác giả Mumtaz và cs [8] lại cho tỷ lệ thấp hơn nhiêu $12,6 \%$. Do vậy tỷ lệ âm tính của dấu ấn CK20 cũng thay đổi theo từng nghiên cứu.

Đối với những khối u bộc lộ dương tính với CK20, nghiên cứu của chúng tôi cũng như nhiều nghiên cứu khác lựa chọn điểm cắt $10 \%$ để chia làm 2 nhóm dương tính ổ và dương tính lan tỏa. Nghiên cứu của Harnden và cs cho thấy nhóm u có kiểu hình bộc lộ CK20 bất thường với 60,9\% còn tác giả Mumtaz và cs [8] tỷ lệ các u có kiểu hình bộc lộ dương tính lan tỏa và dương tính ổ lần lượt là $54,7 \%$ và $32,6 \%$. Bên canh đó Burge và cs [7] cho kết quả với $60 \%$ các trường hợp bộc lộ bất thường. Các kết quả trên khá tương đồng với kết quả nghiên cứu của chúng tôi cho thây dấu ấn CK20 dương tính với 67 ca trong đó dương tính ổ có $27 \mathrm{ca}(27,3 \%)$ và dương tính lan tỏa có 40 ca (40,4\%). Tuy nhiên một nghiên cứu trong nước của tác giả Lê Thanh Xuân [3] cho kết quả với kiểu hình bộc lộ CK20 dương tính ổ là $16 \mathrm{ca}(31,4 \%)$ và khối u dương tính lan tỏa với CK20 chỉ có 10 ca (17,6\%), thấp hơn nghiên cứu của chúng tôi và các tác giả nước ngoài.

Đồng thời đối với các typ mô học dấu ấn CK 20 bộc lộ âm tính chủ yếu với typ nhú chiếm tới $31 / 32$ ca âm tính. Đối với các typ còn lai gồm 18 ca, dấu ấn CK20 tâp trung chủ yếu là dương tính trong khi đó chỉ có 01 ca $(5,6 \%)$ bộc lộ âm tính. Và trong nghiên cứu này chúng tôi cũng nhận thấy có mối liên quan có ý nghĩa thống kê giữa các typ mô học với bộc lộ mức độ CK20 với giá trị $p=0,003<0,05$.

Trong bảng 3.3 đối với khối u có độ mô học thấp trong nghiên cứu của chúng tôi thấy có 18 ca được phân tích dấu ấn CK20 trong đó có 15 ca âm tính $(83,3 \%)$ chiếm tỷ lệ cao. Ngược lại chỉ $03 \mathrm{ca}(16,7 \%)$ dương tính chiếm tỷ lệ thấp trong đó có $01 \mathrm{ca}(5,6 \%)$ dương tính ổ và $02 \mathrm{ca}$ $(11,1 \%)$ dương tính lan tỏa. Kết quả này cũng có phần nào tương đồng với tác giả Lê Thanh Xuân [3] lại cho rằng nhóm u có độ mô học thấp có kiểu hình bộc lộ CK20 chiếm phần lớn $(72,7 \%)$ ca âm tính. Và số ca có khối u dương tính chiếm $27,3 \%$ trong đó với CK20 dương tính ổ chiếm tỷ lệ cao hơn: 7 ca chiếm 21,2\% và có 02 ca dương tính lan tỏa với CK20 chiếm 6,1\%. Mặc dù vây các kết quả này đều có ý nghĩa thống kê với $p<0,05$.

Đối với khối u có độ mô học cao trong nghiên cứu của chúng tôi nhận thây số ca âm tính giảm có 17 ca $(21 \%)$ âm tính và số ca dương tính chiếm phần lớn với 54 ca (79\%). Kết quả này tương đồng với tác giả Lê Thanh Xuân [3] cũng cho rằng trong nhóm u độ cao, chỉ có $02 \mathrm{TH}$ âm tính với dấu ấn CK20, Tương tự như vây là Pham Thuần Manh và Lê Trung Tho đánh giá kiểu hình bộc lộ bình thường với CK20 (chỉ giới hạn ở lớp tể bào dù hoắc rải rác ở các tế bào thuộc lớp trung gian) và bộc lộ bất thường (bộc lộ dương tính cục bộ đến lan tỏa trên toàn bộ bề dày biểu mô hoặc mất bộc lộ). Kết quả cho thấy trong nhóm u độ cao, tî lệ kiểu hình bộc lộ bình thường (âm tính) chiếm 11,1\%. Một số tác giả nước ngoài khác như tác giả Mumtaz và cs [8] còn cho kết quả thấp hơn với tỷ lệ âm tính là $8,3 \%$ và tỉ lệ bộc lộ dương tính chiếm tỷ lệ vượt trội trong đó dương tính lan tỏa của CK20 là $68,8 \%$, tî lê dương tính ổ là $22,9 \%$.

Đánh giá về giai đoạn khối u ung thư biểu mô đường niệu trong bảng 3.4. Trong nghiên cứu của chúng tôi với 99 bệnh nhân thấy đối với giai đoạn chưa xâm nhập cơ pT1 có 42 ca trong đó 23 ca $(54,8 \%)$ âm tính, 19 ca $(45,2 \%)$ dương tính thì có 08 ca dương tính ổ và 11 ca dương tính lan tỏa. kết quả của chúng tôi có khác biệt với tác giả Harnden và cs khi nghiên cứu trên 51 trường hợp các u giai đoạn chưa xâm nhập cơ 
cũng thấy kiểu hình bộc lộ bất thường (dương tính) hay gặp hơn với $41 \mathrm{ca}(80,4 \%)$, kiểu hình bộc lộ bình thường (âm tính) chỉ gặp ở $10 \mathrm{ca}$ $(19,6 \%)$. Tuy nhiên kết quả của chúng tôi lại phù hợp với tác giả Desai và cs khi nghiên cứu số lượng bệnh nhân cao hơn với trên 120 ca lại cho rằng trong nhóm u giai đoạn Ta có $46,6 \%$ bộc lộ bình thường hay âm tính. Trong nghiên cứu của chúng tôi cho thấy ở giai đoạn xâm nhập pT2-4 có 57 ca thì số ca âm tính lại thấp khi chỉ có $09 \mathrm{ca}$ $(15,8 \%)$ và số ca dương tính chiếm ưu thế với 48 ca $(84,2 \%)$ trong đó có 19 ca dương tính ổ và 29 ca dương tính lan tỏa. Kết quả này cho thây có mối liên quan giữa giai đoạn khối u với mức độ bộc lộ dấu ấn CK20 có ý nghĩa thống kê với $p=0,001<0,05$. Cũng trong nghiên cứu của Yin và Leong[9] nhận thấy mối liên quan giữa bộc lộ CK20 dương tính với độ mô học cũng như giai đoạn bệnh học của u $(p=0,001)$, đồng thời nghiên cứu chỉ ra mối liên quan giữa sự bộc lộ bất thường của CK20 với khả năng tái phát cao hơn ở những khối u giai đoạn và độ mô học cao hơn.

Tóm lại dấu ấn CK20 là một yếu tố quan trọng đánh giá sự liên quan với độ mô học và giai đoạn phát triển của khối u UTBMTN cũng như dự báo độc lập về sự tái phát, tiến triển khối u.

\section{KẾT LUẬN}

Dấu ấn miễn dịch CK20 có tỷ lệ bộc lộ cao ở những u không cấu trúc nhú $(94,4 \%)$, có độ mô học cao $(79 \%)$, thuộc giai đoạn xâm nhập cơ $(84,2 \%)$ hơn là ở những u có cấu trúc nhú đơn thuần $(61,7 \% ; \mathrm{p}=0,003)$, có độ mô học thấp $(16,7 \% ; p=0,000)$ và giai đoạn không xâm nhập cơ $(45,2 \% ; p=0,001)$.

\section{TÀI LIÊU THAM KHẢO}

1. Nguyễn Phúc Cương, Nguyễn Sỹ Lánh, và Nguyến Phương Hồng (2002), "Nghiên cứu hình ảnh giải phấu bệnh của ung thư biểu mô đài bể thận," Báo cáo khoa học tại bệnh viện Việt Đức- Hà Nội.

2. Moch $H$, Humphrey $P A$, Ulbright TM et al (2016), "WHO classification of tumours of the urinary system and male genital organs. 4th Edition.World Health Organization," International Agency for Research on Cancer (IARC), vol. 8.

3. Lề Thanh Xuân (2020), "Đặc điểm mô bệnh học và sự bộc lộ các dấu ấn hoá mô miễn dịch CK20, P53, Ki6̧̧ trong ung thư biểu mô nhú đường niệu," luận vặn thạc sỹ y học. đại học y hà nội.

4. Nguyển Vằn Hưng và ìgưyến Thị Hồng Điêp (2010), "Nghiên cứu mô bệnh học, một số triệu chứng lâm sàng và cận lâm sàng của ung thư biểu mô tiết niệu," Tạp chí Y̛ học thực hành, vol. 4, p. 714 .

5. Bertz $S$, Otto $W$, Denzinger $S$ et al(2014), "Combination of CK20 and Ki-67 immunostaining analysis predicts recurrence, progression, and cancer-specific survival in PT1 urothelial bladder cancer," European urology, vol. 65(1):, pp. 218-226.

6. Xiao $X$, Hu R, Deng F-M et al(2017), "Practical applications of immunohistochemistry in the diagnosis of genitourinary tumors. " Archives of pathology \& laboratory medicine., vol. 141(9), pp. 1181-1194.

7. Burger $M$, Denzinger $S$, Hartmann $A$ et al (2007), "Mcm2 predicts recurrence hazard in stage Ta/T1 bladder cancer more accurately than CK20, Ki67 and histological grade.," British journal of cancer, vol. 96(11), pp. 1711-1715.

8. Mumtaz S, Hashmi AA, Hasan SH et al(2014), "Diagnostic utility of p53 and CK20 immunohistochemical expression grading urothelial malignancies," International archives of medicine, vol. 7(1), p. 36.

9. Yin $H^{\prime}$ and Leong $A S-Y(2004)$, "Histologic grading of noninvasive papillary urothelial tumors: validation of the 1998 WHO/ISUP system by immunophenotyping and follow-up.," American journal of clinical pathology, vol. 121(5), pp. 679-687.

\section{ĐÁNH GIÁ KẾT QUẢ ĐÎ̂̀U TRI PHẪU THUÂT XUẤT HUYẾT TIÊU HÓA CAO DO UNG THƯ HANG MỐN VII DẠ DÀY}

\section{TÓM TẮT}

Xuất huyết tiêu hóa $(\mathrm{XHTH})$ do ung thư hang môn vị dạ dày là một cấp cứu ngoại khoa ngày càng xuất hiện với tỉ lệ cao. Bên cạnh những trường hợp XHTH

\footnotetext{
${ }^{1}$ Bệnh viện $K$ Trung ương

2Trường Đại học Y Dược Thái Nguyên

Chịu trách nhiệm chính: Thái Nguyên Hưng

Email: Thainguyenhung70@gmail.com

Ngày nhận bài: 13.5 .2021

Ngày phản biện khoa học: 29.6.2021

Ngày duyệt bài: 12.7.2021
}

\section{Thái Nguyên Hưng1, Bùi Thanh Thiện ${ }^{2}$}

nhẹ, triệu chứng lâm sàng không rõ ràng, nghèo nàn. Nhiếu trường hợp bệnh nhân XHTH đến muộn, mất máu nặng sốc mất máu đòi hỏi phải xử trí cấp cứu, vừa hồi sức vừa mổ. Cắt da dày vét hach là phương pháp chủ yếu trong điều trị ung thư dạ dày (UTDD) tuy nhiên trong những trường hợp bệnh nhân đến muộn, thiếu máu nặng, mạch huyểt áp không ổn định sốc mất máu phẫu thuật còn gặp nhiều khó khăn đòi hỏi cắt dạ dày triệt căn hay chỉ cắt dạ dày làm sạch cầm máu. Bởi vậy chúng tôi tiến hành nghiên cứu này với 2 mục tiêu: (1) Mô tả đặc điểm lâm sàng, cận lâm sàng của bệnh nhân xuất huyết tiêu hóa cao do ung thư hang môn vị dạ dày. (2)Đánh giá kết quả sớm điều trị phẫu thuật xuất huyết tiêu hóa cao do ung 